\title{
The Effect of Student-Directed Transition Planning With a Computer-Based Reading Support Program on the Self- Determination of Students With Disabilities
}

The Journal of Special Education 45(2) 104-117

(C) Hammill Institute on Disabilities 201 I Reprints and permission: http://www. sagepub.com/journalsPermissions.nav DOI: 10.1 I 77/0022466909358916 http://journalofspecialeducation sagepub.com

\author{
Youngsun Lee', Michael L. Wehmeyer', Susan B. Palmer', \\ Kendra Williams-Diehm ${ }^{3}$, Daniel K. Davies ${ }^{4}$, and Steven E. Stock ${ }^{4}$
}

\begin{abstract}
The purpose of this study was to investigate the impact of student-directed transition planning instruction (Whose Future Is It Anyway? curriculum) with a computer-based reading support program (Rocket Reader) on the self-determination, selfefficacy and outcome expectancy, and transition planning knowledge of students with disabilities. This study employed a pre- and postmeasure design with 168 middle school students with disabilities who were assigned to an experimental group $(n=86)$ and control group $(n=82)$. The results of the study demonstrated that self-determination, self-efficacy, and outcome expectancy for education planning improved through the application of Rocket Reader. Avenues are discussed for promoting middle school students' self-determination in their transition planning, as are implications for future research.
\end{abstract}

\section{Keywords}

self-determination, transition planning, middle/junior high school students, technology, reading supports

Research examining the personal attributes of successful adults with disabilities has found that people who are more self-determined are more independent and have a better quality of life (Agran, Blanchard, \& Wehmeyer, 2000; Wehmeyer \& Palmer, 2003; Wehmeyer \& Schwartz, 1997, 1998). Self-determination, defined by Wehmeyer (2005) as "volitional actions that enable one to act as the primary causal agent in one's life and to maintain or improve one's quality of life" (p. 117), has been identified as being predictive of the attainment of these valued life outcomes for adolescents and adults with disabilities. Specifically, research has found that adolescents with disabilities who are more self-determined when they leave school are more likely to be employed and live independently than are their peers who are less self-determined (Wehmeyer \& Palmer, 2003; Wehmeyer \& Schwartz, 1997). Moreover, research has found that enabling students to acquire and exercise skills leading to enhanced self-determination is a strategy that leads to more positive education outcomes (Palmer, Wehmeyer, Gipson, \& Agran, 2004).

Although promoting self-determination is considered a best practice in transition services, research has found that students' Individualized Education Programs (IEPs) frequently do not contain goals related to teaching abilities promoting self-determination (Agran, Snow, \& Swaner,
1999; Mason, Field, \& Sawilowsky, 2004; Wehmeyer, Agran, \& Hughes, 2000). Therefore, preparing students to be involved in the development and implementation of their IEPs, including being meaningfully engaged in their IEP meeting and in monitoring their IEP goal attainment, is a strategy that has potential for significantly affecting student self-determination and self-advocacy skills and leading to more positive adult outcomes. Izzo and Lamb (2002) suggested that school districts that are seeking to encourage self-determination and positive school outcomes for students with disabilities should facilitate student-centered IEP meetings and self-directed learning models. Similarly, the National Center on Secondary Education and Transition (2004) recommended promoting and supporting studentcentered and student-run IEP meetings.

\footnotetext{
'Inha University, Incheon, Korea

${ }^{2}$ University of Kansas, Lawrence, KS, USA

${ }^{3}$ University of Oklahoma, Norman, OK, USA

${ }^{4}$ Colorado Springs, CO, USA
}

\section{Corresponding Author:}

Youngsun Lee, Department of Education, Inha University,

YongHyung-dong, Nam-gu, Incheon, Korea

E-mail:ylee@inha.ac.kr 


\section{Students' Participation in IEP Meetings}

Recently, one area of focus of research in self-determination has involved examination of the involvement of students with disabilities in their transition planning activities (Zhang \& Stecker, 2001). The Individuals with Disabilities Education Act Amendments of 2004 continued to require that students aged 16 and older be invited to their IEP meetings if transition services are to be discussed. Nevertheless, students' participation in their IEP meetings is still low. Martin and colleagues (2006) found that although $71 \%$ of students attended their immediately previous IEP or transition planning meeting, $56 \%$ indicated that they had not been told the purpose of the meeting, $76 \%$ had not prepared for the meeting, and 59\% had not helped in any way to identify goals. Similarly, student involvement in transition planning is essentially nonexistent or passive (i.e., decisions are made by others). In other words, when students with disabilities have been present at their IEP meetings, they have rarely been included in the conversation or been asked their preferences (Power et al., 2001). Furthermore, teachers, parents, and other professionals did little to prepare students for their IEP and transition planning meetings (Thoma, Rogan, \& Baker, 2001). In fact, Thoma and colleagues (2001) suggested that the atmosphere in such meetings was more agenda oriented and adult focused than student centered or student directed.

Therefore, more emphasis must be placed on specifically teaching students how to participate in transition-related discussions. Several curricular materials and programs have been developed to address the need for instruction to promote student involvement and self-determination. Test and colleagues (2004) reviewed programmatic efforts to promote student participation in their IEP meetings (e.g., The Self-Directed IEP, TAKE CHARGE for the Future, Next S.T.E.P., Student-Led IEPS, and Whole Life Planning). They found that (a) the use of these curricular materials and programs to teach students the skills to enhance their participation before IEP meetings and (b) the use of person-centered planning increased students' involvement in their meetings. Providing students with disabilities instruction to promote their involvement in educational planning and decision making is thus an important component of high-quality transition services (Test et al., 2004).

\section{Engaging Students With Disabilities and Technology}

Among the barriers for many students with disabilities with regard to receiving effective instruction to promote active involvement in transition planning has been their inability to interact with materials, typically print based, that are designed to teach them these skills. Many students with disabilities have reading impairments. As such, it is difficult for them to independently access text-based content that serves as the basis for instruction (Elder-Hinshaw \& MansetWilliamson, 2006), including instruction to promote student involvement.

A critical feature of efforts to engage students with disabilities in instruction on topics such as student involvement and self-advocacy involves the use of universally designed instructional technology to provide teachers with the means to expand ways in which they present lessons to students with disabilities. In other words, universally designed instructional materials provide flexible options for students to receive content information and respond to instruction (Rose \& Meyer, 2002).

Several studies have demonstrated the utility and efficacy of cognitively accessible multimedia palmtop or desktop computer applications to enable youth and adults with disabilities to independently access electronic books and documents by listening to recorded or computer-generated speech (Davies, Stock, \& Wehmeyer, 2003; Wehmeyer et al., 2006). In addition, the use of technology with a speech component provides a bimodal (auditory and visual) approach to instruction that supports students who have limited reading abilities.

This study examined the effect of student-directed transition planning with a computer-based reading support program on the self-determination of students with disabilities in middle school classrooms. Specifically, we sought to answer the following questions:

Does implementation of a student-directed transition planning process with students with reading impairments improve student self-determination, self-efficacy and outcome expectancy for transition planning, and transition planning knowledge? Does implementation of a student-directed transition planning process with a cognitively accessible computer-based reading program improve the self-determination, self-efficacy and outcome expectancy for transition planning, and transition planning knowledge of students with reading impairments?Are there any differences on student self-determination, self-efficacy and outcome expectancy for transition planning, and transition planning knowledge between a group receiving a student-directed transition planning process and a group receiving a student-directed transition planning process with a cognitively accessible computer-based reading program?

\section{Method}

\section{Participants}

Participants were 168 junior high and middle school students receiving special education services, as identified by educators as requiring supports with regard to reading. 
Students eligible for the study were identified as having reading difficulties by their teachers and through standardized reading test scores used in each school district. These students were recruited from 12 campuses at six school districts in the midwestern United States. Table 1 describes the characteristics of each group, including gender, age, disability, ethnicity, estimated level of intelligence, geographic area information, and typical educational setting. In addition, the teacher version of one measure of self-determination used in this study, the AIR Self-Determination Scale-Educator, was administered as a pretest only and is thus presented as demographic data in this table. The results of a preliminary chi-square test indicated that the two groups did not differ significantly on the AIR Self-Determination Scale-Educator scores (for control group, $M=76.07, S D=12.54$; for experimental group, $M=72.53, S D=12.66$ ), but there was a statistical difference between the two groups in the estimated IQ level of students, $\chi^{2}(3, N=168)=23.95, p<.01$. That is, students in the control group had a higher IQ than those in the experimental group.

To investigate the differences between groups depending on the use of the technology-based reading supports, we randomly assigned all participants to either an experimental group ( $n=86)$ or a control group $(n=82)$. Random assignment occurred at the level of the school campus. The decision to randomize at the campus level and not by teacher or student was a function of the way in which special education services were provided in these districts. If the randomization was to occur by student, special education teachers would likely end up teaching students in both the control group and the treatment group. Similarly, because special educators often coteach, assigning by teacher might result in teachers being in the same school but in different groups and consequently teaching students in both groups as well.

Participating students received student-directed transition planning instruction with or without the support of a computer-based reading support program in their special education classes under their participating teachers' direct supervision. Twenty-five teachers were involved in the study: 11 in the control group (44\%) and 14 in the treatment group (56\%). For teachers in the control group, the average number of years teaching students with disabilities or students at risk was $16.09(S D=5.94)$, and their mean age was $41.10(S D=9.41$; excluding one teacher who declined to provide her or his age). For teachers in the experimental group, the average number of years teaching students with disabilities or students at risk was $14.43(S D=8.99)$, and their mean age was $44.08(S D=6.54$; excluding one teacher who declined to provide her or his age).

\section{Procedure}

We employed a randomized trial, including control group with pretest and posttest design (Shadish, Cook, \& Campbell,
Table I. Demographic Description of the Control and Experimental Groups

\begin{tabular}{|c|c|c|c|c|}
\hline & \multicolumn{2}{|c|}{$\begin{array}{l}\text { Control group } \\
\quad(n=82)\end{array}$} & \multicolumn{2}{|c|}{$\begin{array}{l}\text { Experimental } \\
\text { group }(n=86\end{array}$} \\
\hline & $n$ & $\%$ & $n$ & $\%$ \\
\hline \multicolumn{5}{|l|}{ Gender } \\
\hline Female & 24 & 29.3 & 20 & 23.3 \\
\hline Male & 58 & 70.7 & 66 & 76.7 \\
\hline Age & \multicolumn{2}{|c|}{$\begin{array}{l}M=13.29 \\
(S D=0.78)\end{array}$} & \multicolumn{2}{|c|}{$\begin{array}{l}M=13.89 \\
(S D=0.78)\end{array}$} \\
\hline \multicolumn{5}{|l|}{ Disability } \\
\hline ADD/ADHD & 5 & 6.1 & 9 & 10.5 \\
\hline $\begin{array}{l}\text { Emotional or behavioral } \\
\text { disorders }\end{array}$ & 6 & 7.3 & 12 & 14.0 \\
\hline Mental retardation & I & 1.2 & 22 & 25.7 \\
\hline Speech disorder & 9 & 11.0 & 6 & 7.0 \\
\hline Other health impairment & 8 & 9.8 & 5 & 5.8 \\
\hline Autism & 4 & 4.9 & 3 & 3.5 \\
\hline Learning disability & 49 & 59.8 & 29 & 33.7 \\
\hline \multicolumn{5}{|l|}{ Ethnicity } \\
\hline Caucasian & 50 & 61.0 & 45 & 52.3 \\
\hline African American & 9 & 11.0 & 26 & 30.2 \\
\hline Hispanic/Latino & 20 & 24.4 & II & 12.8 \\
\hline Asian/Pacific Islander & 2 & 2.4 & 3 & 3.5 \\
\hline $\begin{array}{l}\text { Native American/Alaskan } \\
\text { Native }\end{array}$ & 1 & 1.2 & 1 & 1.2 \\
\hline \multicolumn{5}{|l|}{ IQ level } \\
\hline IQ within normal limit $(\geq 70)$ & 79 & 96.3 & 58 & 67.4 \\
\hline $\begin{array}{l}\text { Mild mental retardation } \\
\quad(60-69)\end{array}$ & 1 & 1.2 & 18 & 20.9 \\
\hline $\begin{array}{l}\text { Moderate mental } \\
\text { retardation }(45-60)\end{array}$ & 2 & 2.4 & 8 & 9.3 \\
\hline Severe/profound $(\leq 44)$ & 0 & 0.0 & 2 & 2.3 \\
\hline \multicolumn{5}{|l|}{ Reading level } \\
\hline Nonreader & 4 & 4.9 & 7 & 8.1 \\
\hline Basic (below grade level) & 49 & 59.8 & 62 & 72.1 \\
\hline Proficient (at grade level) & 28 & 34.1 & 14 & 16.3 \\
\hline Exemplary (above grade level) & 1 & 1.2 & 3 & 3.5 \\
\hline \multicolumn{5}{|l|}{ Geographic area } \\
\hline Urban & 0 & 0.0 & 40 & 46.5 \\
\hline Suburban & 74 & 90.2 & 46 & 53.5 \\
\hline Rural & 8 & 9.8 & 0 & 0.0 \\
\hline \multicolumn{5}{|l|}{ Typical educational setting } \\
\hline Resource room & 25 & 30.5 & 18 & 20.9 \\
\hline Self-contained & 0 & 0.0 & 8 & 9.3 \\
\hline Mainstream & 2 & 2.4 & 5 & 5.8 \\
\hline General education & 55 & 67.1 & 55 & 64.0 \\
\hline $\begin{array}{l}\text { Self-determination score } \\
\text { (AIR-E) }\end{array}$ & \multicolumn{2}{|c|}{$\begin{array}{c}M=76.07 \\
(S D=12.54)\end{array}$} & \multicolumn{2}{|c|}{$\begin{array}{c}M=72.53 \\
(S D=12.66)\end{array}$} \\
\hline
\end{tabular}

Abbreviations: $A D D=$ attention deficit disorder;ADHD = attentiondeficit/hyperactivity disorder;AIR-E = AIR Self-Determination Scale-Educator.

2002), to address the research questions. Participants were recruited from school districts by contacting school district personnel to obtain permission to conduct the project. Once 
we obtained district-level permission for pre- and posttests and implementation of the intervention, project personnel worked with district representatives to identify and contact special education teachers to recruit them for participation in the study. Teachers were invited to participate in a 1-hour initial meeting about the study, which included training on the Whose Future Is It Anyway? (WFA) student-directed transition planning process, the intervention to promote student involvement implemented in the study. Teachers attending the meeting received the WFA Coach's Guide, a manual for implementing WFA lessons. All teachers in the control and experimental groups were provided training to implement the WFA process, focusing on objectives and core elements of each unit and teachers' roles when implementing the WFA process. At the end of training, teachers were provided consent forms to sign if they wanted to participate. If they did, they were then provided student consent forms to send to parents/guardians of students for whom they had instructional responsibilities and who met the study criteria; that is, the student was in junior high or middle school, was between the ages of 12 and 16, was receiving special education services, and was identified as having difficulty reading. Table 1 provides details about student disability categories.

When informed consent to participate was obtained from each teacher and his or her students, the WFA materials were given to each student in the experimental and control groups. Teachers in the experimental group were then provided an additional 2-hour teacher training session about Rocket Reader, a cognitively accessible text reader (details provided subsequently), and were provided digital versions of the WFA lessons for use with the Rocket Reader device. Teachers in the experimental group were also trained to set up student accounts for each student to use Rocket Reader. Furthermore, teachers in both groups received ongoing supports from researchers throughout this study. After initial and technology-teacher trainings, WFA lessons were provided to students in the control and experimental groups. All students in both groups could access the same components of WFA with or without Rocket Reader. They received teacher-led or student-directed instruction using the WFA curriculum. Components and content delivered by teachers were the same for both groups. Students in experimental group, however, could access WFA lessons via a cognitively accessible text reader.

\section{Intervention}

Intervention to promote student involvement. WFA is a student-directed transition planning process (Wehmeyer et al., 2004) emphasizing students' preferences, needs, and interests pertaining to their transition from secondary education to adult life. The process consists of six sections and
Table 2. Selected Sessions of Whose Future Is It Anyway? per Program Area

\begin{tabular}{lrl}
\hline Program area & Session & \multicolumn{1}{c}{ Topic } \\
\hline Getting to Know You & I & Your preferences and interests \\
& 2 & Disability \\
& 3 & Your unique learning needs \\
& 4 & Supports \\
Communicating & 5 & Communicating in small groups \\
& 6 & Body language and assertiveness \\
Making Decisions & 7 & Advocating and appealing \\
Goals, Objectives, and & 8 & Introducing DO IT! \\
the Future & 9 & Identifying goals in your plan \\
Thank You, Honorable & 10 & Being a good team member \\
Chairperson & & \\
\hline
\end{tabular}

36 sessions introducing students to the concept of transition and transition planning and enabling them to self-direct learning related to (a) having self-awareness and disability awareness, (b) decision making about transition-related outcomes, (c) identifying and securing community resources to support transition services, (d) writing and evaluating goals and objectives, (e) communicating effectively in small groups, and (f) developing skills to become an effective team member, leader, or self-advocate. Throughout this process, students are expected to learn how to be meaningfully involved in their transition planning process and/or IEP meetings. Previous research with the $W F A$ process showed that involved students gained knowledge about transition planning, held more positive efficacy expectations for planning, and were more self-determined (Wehmeyer \& Lawrence, 1995).

The units and lessons from the WFA process were designed for use over the course of a full academic school year. Owing to time constraints for the study and based on what would be a priority for middle school students, only selected sessions from the WFA process were implemented. The lead researcher and three other researchers with knowledge of the WFA process reviewed all sessions and selected several as being applicable for the student population in the study. As a result, 10 sessions were identified to be implemented with all students in the study (see Table 2). These sessions provide relevant information for middle school students and, generally, opportunities for participating students to think about and identify future goals and focus on important skills for the transition planning meeting. Participating teachers were asked to work with their students on each lesson for 1 week.

Cognitively accessible audio reader. The Rocket Reader is a computer software program designed for students with disabilities that affect reading. It enables them to access and utilize electronic materials in audio formats. Print material 
can be recorded in audio formats for use with the software. The Rocket Reader software is operated on the Pocket PC palmtop computer platform. The user interface is highly visual and auditory based, and it provides consistent feedback and interaction with the user to maximize usability and simplicity. Nonreaders can sequentially tap each book image and listen to the name until they find the book they are seeking. The audio prompt then instructs users to tap the book a second time if they would like to open that book and begin listening. From left to right, the available buttons on the screen are an orange Restart button, a red Stop button, and a green/blue Read/Pause button. The Restart button restarts the book from the beginning; the Stop button stops the book and immediately returns to the book selection screen; and the Read/Pause button plays and pauses the book, changing appearance based on the current play state. In summary, the Rocket Reader audio player was designed for use by individuals with reading difficulties; it provides a simplified interface and a limited number of large, easily selectable buttons; and it uses visual and audio cues and instructions to help the user operate the system. This study used a modified version of the Rocket Reader, with the only difference between the study version and the regular version being that the former was compiled to be run on a desktop or notebook PC instead of the pocket computer. Students in the experimental group could access the content delivered in the WFA curriculum independently or with teacher's supports, as needed.

\section{Instrumentation}

The effectiveness of the student-directed transition planning instruction, with and without access to electronic materials provided in an audio format (experimental group and control group, respectively), was measured with multiple instruments, including the Arc's Self-Determination Scale (Wehmeyer \& Kelchner, 1995), the AIR Self-Determination Scale (Wolman, Campeau, DuBois, Mithaug, \& Stolarski, 1994), the Whose Future Knowledge Scale, and the SelfEfficacy and Outcome Expectancy for Educational Planning scale. Researchers administered these measures and provided supports as needed for students to complete each.

Measuring self-determination. To measure student selfdetermination, we collected data from the Arc's Self-Determination Scale and the AIR Self-Determination Scale. The Arc's Self-Determination Scale is a student self-report measure of global self-determination. It consists of a 72-item selfreport scale that provides data on overall self-determination by measuring individual performance on four essential characteristics of self-determined behavior (autonomy, selfregulation, psychological empowerment, and self-realization) identified by Wehmeyer, Kelchner, and Richards (1996). The scale includes 4-point Likert-type scale items, story completion items (i.e., the beginning and ending of a story are provided and the student writes the middle section), items that require the student to identify goals and break them into smaller steps, and items that require students to choose between two options. The scale can be completed by the student independently, or it can be read to the student. On the scale, 148 points are available, and higher scores reflect higher levels of self-determination. The Arc's SelfDetermination Scale was normed with 500 students with and without cognitive disabilities in rural, urban, and suburban school districts in five states (Wehmeyer et al., 1996). The scale's concurrent criterion-related validity was established by showing relationships between the Arc's SelfDetermination Scale and conceptually related measures. The scale had adequate construct validity (including factorial validity established by repeated factor analyses), discriminative validity, and internal consistency (Cronbach alpha $=.90$; Wehmeyer, 1996). The scale has been used to document the importance of self-determination for positive adult outcomes (Wehmeyer \& Palmer, 2003; Wehmeyer \& Schwartz, 1998) and student involvement in educational planning (Cross, Cooke, Wood, \& Test, 1999; Sands, Spencer, Gliner, \& Swaim, 1999; Zhang, 2001) for youth with disabilities, and it has provided validation of interventions to promote self-determination (Wehmeyer et al., 2000).

The other measure of self-determination implemented, the AIR Self-Determination Scale (Wolman et al., 1994), measures an individual's capacity for and opportunity to act in a self-determined manner. The purposes of this scale are to (a) assess and develop a profile of the student's level of self-determination, (b) identify areas of strength and areas needing improvement, (c) identify specific educational goals and objectives that can be incorporated into the student's IEP, and (d) develop strategies to build the student's capacities and opportunities to become more self-determined and better prepared for a maximally independent adult life. The AIR Self-Determination Scale has three sections within in the Capacity subscale (Ability, Knowledge, and Perceptions) and two sections within the Opportunity subscale (Opportunity at School and Opportunity at Home). Within each section are two items that focus on thinking, two on doing, and two on adjusting.

In this study, data on the AIR-Student (AIR-S) version, as with the Arc's Self-Determination Scale, was collected pre- and postintervention. Capacity and Opportunity subscale scores can be calculated, as can a total self-determination score, which is the sum of the capacity and opportunity subscales. On this scale, a 5-point Likert-type scale $(1=$ never, $5=$ always) is used to rate students' self-determination, and 120 points are available. The Capacity subscale consists of questions pertaining to things that students do that are related to self-determination (Things I Do subscale) and 
how students feel about performing these self-determined behaviors (How I Feel subscale). The Opportunity subscale consists of questions regarding students' perceptions of their opportunities to perform self-determined behaviors at home and at school. Therefore, the AIR-S consists of 18 questions rated on a scale of 1 (never) to 5 (always).

The AIR-S and AIR-Educator (given only as a pretest measure and used to provide demographic information) were developed and normed with 450 students with and without disabilities and their teachers in California and New York (Wolman et al., 1994). Both versions of the scale were demonstrated to have adequate reliability and validity in the measurement of self-determination for students with and without disabilities. Although correlations between the AIR-S and AIR-Educator were not reported, students with disabilities tended to rate their capacity for self-determination, as measured by the Capacity subscale, higher than their special education teachers did, whereas the reverse pattern was seen on the school opportunities subscale (Mithaug, Campeau, \& Wolman, 2003).

Measuring students' knowledge about transition planning meeting. To measure knowledge about transition planning and the degree to which students benefited from instruction utilizing the WFA process, the WFA Knowledge Test (Wehmeyer \& Lawrence, 1995), a criterion-referenced assessment of knowledge presented in the WFA process, was administered before and after instruction. The assessment contains a total of 28 questions, with students asked to select one best answer from four options for each question. Questions were taken directly from lessons in the WFA process. Students are awarded one point if they select the correct answer and no points if they do not. For the purpose of the study, only questions pertaining to the lessons implemented were included, resulting in 20 items. Five points were given to correct answers, and no points were given to the incorrect answers; therefore, possible scores ranged from 0 to 100 .

Measuring self-efficacy for educational planning. Selfefficacy refers to the "conviction that one can successfully execute the behavior required to produce a given outcome" (Bandura, 1977, p. 193), and outcome expectations refers to a person's belief that if a specific behavior is performed, it will lead to the anticipated outcome. Students completed a 20-item questionnaire constructed by Wehmeyer and Lawrence (1995) to measure the degree to which they believed (a) that they could perform the necessary behaviors to successfully participate in their transition planning meeting and (b) that if they did perform these behaviors, the desired outcome would result (i.e., they would be allowed to participate in the meeting). The first 10 items on the questionnaire ask students about their beliefs in their ability to participate in an IEP meeting (e.g., purpose of IEP meeting, knowledge of rights, roles of IEP team members, how to communicate preferences). The second set of 10 questions focus on anticipated outcomes (e.g., "If you participate in your IEP meeting, will that affect the transition goals chosen?" "If you speak up, will your rights at the IEP meeting be respected?"). Wehmeyer and Lawrence found that the questionnaire scores were positively and significantly correlated $(r=.36, p=.008)$ with other measures of self-efficacy (e.g., The Self-Efficacy Scale; Sherer et al., 1982).

Social validity feedback form. To assess the social validity of the WFA and Rocket Reader intervention, all students were asked to provide written social validation data by completing a feedback form about the WFA and Rocket Reader, which consisted of four questions for the group receiving $W F A$ and eight questions for the group receiving WFA with Rocket Reader. Moreover, all teachers were asked to complete a feedback form about the intervention, which consisted of 13 questions about the overall effects of intervention, effective lessons, and suggestions for ways to improve the process of implementing the WFA curriculum with middle school students (e.g., adaptation or modifications).

\section{Data Collection}

After we obtained consent to participate from students, we conducted pretests based on the multiple measures of selfdetermination, self-efficacy and outcome expectancy, and transition planning knowledge (previously described). Students in both groups completed the pretests before intervention implementation. Teachers in both groups were asked to contact project personnel for the posttests after completing implementation of the 10 WFA? lessons or at the end of the semester. Classroom teachers collected posttest data upon completion of the WFA lessons using the same instruments for which pretest data were collected.

\section{Data Analysis}

Treatment fidelity. We monitored the fidelity of intervention for implementation for both groups. In this study, we monitored context fidelity by providing 1 hour of training on the $W F A$ process to all special education teachers involved in the study. We monitored compliance fidelity by providing weekly resources via e-mail with teachers to facilitate their effective implementation of the WFA lessons. In addition, we evaluated competence fidelity by asking participating students and teachers to complete the intervention feedback form. Several questions on the form related to implementation of the WFA (e.g., number of completed lessons, degree of difficulty of lessons, and level of understanding of the lesson objectives). Participating teachers reported that they completed an average of 7.0 WFA lessons $(S D=2.09$, range $=4-10)$. Teachers in the control 
group completed an average of 7.4 lessons $(S D=2.25)$ and teachers in an experimental group completed an average of 7.2 lessons $(S D=2.15)$. Eleven teachers completed all lessons.

Additionally, the first author monitored the implementation of the WFA process in control and treatment schools and the use of Rocket Reader in the treatment sites by observing four classrooms (two classrooms in control group and two classrooms in experimental group) and using a checklist that listed the instructional steps and general features of the lesson. Four teachers were observed teaching $98.8 \%$ of the lesson steps, including covering the target objective of the chapter, introducing main ideas clearly, providing opportunities for discussion, and responding to the students' questions and comments by giving clear explanation with positive feedback.

Power analysis. Based on previous research with the WFA (Wehmeyer \& Lawrence, in press), the effect size (Lipsey \& Wilson, 2001) of intervening with the WFA was estimated as measured by the WFA Knowledge Test (Cohen's $d=0.43$ ), the self-efficacy assessment (Cohen's $d=0.50$ ), and the outcome expectancy assessment (Cohen's $d=0.36$ ). These effect sizes indicate that the WFA has a small to moderate impact (WFA Knowledge Test and outcome expectancy assessment) or a moderate impact (self-efficacy assessment). As a result of these individual analyses, a value of 0.40 (Cohen's $d$ ) was selected for use in the power analysis to ensure that adequate power would be achieved to detect a difference between the intervention group and the control group. Based on the information described above, a power analysis was conducted to determine how many students would be needed to achieve a power of 0.80 .

Using formulas specified by Cohen (1988) and the fpower macro (Friendly, 1983), we calculated the power of a one-way analysis of variance (ANOVA) with repeated measures; that is, each participant in both groups was to be tested two times (before and after intervention), to measure his or her level of self-determination, self-efficacy, and outcome expectancy for educational planning. Given the research design, we determined that there would need to be 50 participants in each group, for a total of 100 participants. The final sample size far exceeded this requirement.

Missing data. A small amount of data were missing on several variables. The mean percentage of missing data across the variables in the data set was $0.60 \%$ (range $=0 \%-$ $1 \%$ ). The expectation-maximization imputation algorithm using the "missing value analysis" procedure within SPSS was used to impute the missing data (Acock, 2005), to preserve important characteristics of the data set and to avoid the potential deleterious effects of not including all available data in the data analysis process.

Analytic procedures. Given that data on students in two groups were collected across two times, repeated measures analyses were used to address the research questions about group differences related to students' level of self-determination, perceptions of self-efficacy and outcome expectancy for educational planning, and understanding of transition planning. The repeated measures test can examine a variable in each student before and after an intervention, as well as determine how changes vary between two groups, an intervention and a control group (Green \& Salkind, 2008).

Because we were interested in looking at the effects on the two outcomes separately, we performed separate multivariate analyses of covariance (MANCOVAs) for self-determination and perceptions of self-efficacy and outcome expectancy for educational planning, instead of all dependent variables in combination. First, a repeated measures MANCOVA was conducted to determine the effect of the intervention (WFA curriculum with or without Rocket Reader) on the five dependent variables, including the AIR Self-Determination Scale total score and the four subscale scores of the Arc's SelfDetermination Scale (Autonomy, Self-Regulation, Psychological Empowerment, and Self-Realization). The total score of the Arc's Self-Determination Scale could be mostly affected by the Autonomy subscale, given that it contributes a large portion of the variance to the total score. That is, we could fail to find meaningful changes in other subscales because they contribute only a small portion to the total scores. Therefore, to closely investigate the impact of the intervention, we designated the four subscales of the Arc's Self-Determination Scale as dependent variables. ANOVAs were corrected for type I error rate using the Bonferonni adjustment based on the number of ANOVAs computed subsequently to each multivariate analysis of variance, producing a required significant level of .01. Multiple comparisons were not necessary for the comparisons, because each comparison involved only two groups (Kleinbaum, Kupper, Muller, \& Nizam, 1998).

Second, to determine changes in perceptions of self-efficacy and outcome expectancy for educational planning, we performed a repeated measures MANCOVA. The repeated measures factors were pre- and posttest on two dependent variables: self-efficacy and outcome expectancy. We adjusted alpha levels to .025 using the Bonferonni adjustment based on the number of ANOVAs computed subsequent to each multivariate analysis of variance. Finally, to examine changes in knowledge about the transition planning meeting, we conducted a repeated measures analysis of covariance for students' understanding of the transition planning meeting process measured at two different time points (pre- and posttest).

We made an adjustment for three covariates in three analyses: students' reading proficiency level (teacher reported), previous experience of technology use (also at Time 1), and student's approximate IQ group. 
Table 3. Students' Observed Pre- and Posttest Mean Scores

\begin{tabular}{|c|c|c|c|}
\hline & & Pretest score & Posttest score \\
\hline Test & Group & $M(S D)$ & $M(S D)$ \\
\hline \multirow{2}{*}{$\begin{array}{l}\text { Arc's Self-Determination } \\
\quad \text { Scale }\end{array}$} & Control & 93.01 (16.57) & $96.37(18.84)$ \\
\hline & Eyperimental & $8886(2236)$ & $9260(2255)$ \\
\hline \multirow[t]{2}{*}{ Autonomy } & Control & $58.40(13.58)$ & $60.85(15.43)$ \\
\hline & Experimental & $56.81(17.68)$ & $59.54(18.66)$ \\
\hline \multirow[t]{2}{*}{ Self-Regulation } & Control & $10.90(3.98)$ & II.3I (3.65) \\
\hline & Experimental & $7.42(4.01)$ & $10.17(4.04)$ \\
\hline Psychological & Control & $12.85(2.55)$ & $13.08(2.75)$ \\
\hline \multicolumn{4}{|l|}{ Empowerment } \\
\hline & Experimental & $12.15(3.25)$ & $12.24(3.68)$ \\
\hline \multirow[t]{2}{*}{ Self-Realization } & Control & $10.85(2.48)$ & $11.13(2.67)$ \\
\hline & Experimental & $10.48(3.68)$ & $10.63(2.91)$ \\
\hline \multirow{3}{*}{$\begin{array}{l}\text { AIR Self-Determination } \\
\quad \text { Scale }\end{array}$} & Control & $84.20(15.22)$ & $88.13(13.33)$ \\
\hline & & & \\
\hline & Experimental & $84.30(18.68)$ & $86.43(20.48)$ \\
\hline \multicolumn{4}{|l|}{$\begin{array}{l}\text { Educational planning } \\
\text { assessment }\end{array}$} \\
\hline \multirow[t]{2}{*}{ Self-efficacy } & Control & $18.0 \mid(6.17)$ & $20.90(5.94)$ \\
\hline & Experimental & $16.79(6.35)$ & $21.07(5.44)$ \\
\hline \multirow[t]{2}{*}{ Outcome expectancy } & Control & $19.34(6.04)$ & $22.4 \mathrm{I}(5.23)$ \\
\hline & Experimental & $18.74(6.30)$ & $21.81(5.24)$ \\
\hline Whose Future Is It & Control & $65.99(13.84)$ & 76.34 (13.99) \\
\hline Anyway? Knowledge Test & Experimental & $57.42(16.75)$ & 71.92 (13.77) \\
\hline
\end{tabular}

\section{Results}

Table 3 presents observed pre- and posttest scores of students in both groups.

\section{Self-Determination}

In this sample, the test for homogeneity of dispersion matrices was significant, Box $F(55,88570)=1.53, p<.05$. If sample sizes are unequal and Box $\mathrm{M}$ is significant at $p<$ .001 , then robustness is not guaranteed (Tabachnick \& Fidell, 2001). However, Box M was not significant at this level in this sample, although results of an evaluation of assumptions of homogeneity of slopes assumption were dissatisfactory. The multivariate within subjects time effect on the combined dependent variables was not statistically significant. However, the combined dependent variables were significantly affected by Rocket Reader, Wilk's $\Lambda=.93, F(5,159)=2.46$, $p<.05$, and this association was relatively substantial, partial $\eta^{2}=.07$. These results suggest that, taken as a whole, selfdetermination improved through the application of Rocket Reader. In addition, the interaction effect between time and Rocket Reader was not significant, but this association was modest based on the Wilk's $\Lambda$ criterion, partial $\eta^{2}=.05$.

To investigate the impact of the Rocket Reader intervention on the individual independent variable, we conducted
Table 4. Follow-Up Repeated Measures Analysis of Covariance

\begin{tabular}{|c|c|c|c|c|c|c|}
\hline Source & Measure & Type III SS & $d f$ & MS & $F$ & $\begin{array}{c}\text { Partia } \\
\eta^{2}\end{array}$ \\
\hline \multirow[t]{5}{*}{ Time } & SDSI & 44.55 & I & 44.55 & 0.51 & .003 \\
\hline & SDS2 & 21.65 & I & 21.65 & 2.32 & .014 \\
\hline & SDS3 & 0.02 & I & 0.02 & 0.01 & .000 \\
\hline & SDS4 & I.II & I & I.II & 0.26 & .002 \\
\hline & AIRtotal & 11.50 & I & 11.50 & 0.16 & .001 \\
\hline \multirow[t]{5}{*}{ Time $\times R R$} & SDSI & 5.43 & I & 5.43 & 0.06 & .000 \\
\hline & SDS2 & 76.39 & I & 76.39 & $8.18^{*}$ & .048 \\
\hline & SDS3 & 0.20 & I & 0.20 & 0.04 & .000 \\
\hline & SDS4 & 0.13 & I & 0.13 & 0.03 & .000 \\
\hline & AIRtotal & 8.50 & I & 8.50 & 0.12 & .001 \\
\hline \multirow[t]{5}{*}{ Error (time) } & SDSI & $14,298.10$ & 163 & 87.72 & & \\
\hline & SDS2 & I,522.22 & 163 & 9.34 & & \\
\hline & SDS3 & 761.49 & 163 & 4.67 & & \\
\hline & SDS4 & 695.85 & 163 & 4.27 & & \\
\hline & AIRtotal & ||$, 63 \mid .74$ & 163 & 71.36 & & \\
\hline
\end{tabular}

Abbreviations:AIRtotal = AIR Self-Determination Scale; $R R=$ Rocket Reader; SDSI = Autonomy subscale of the Arc's Self-Determination Scale; SDS2 = Self-Regulation subscale of the Arc's Self-Determination Scale; SDS3 = Psychological Empowerment subscale of the Arc's Self-Determination Scale; SDS4 = Self-Realization subscale of the Arc's Self-Determination Scale. $* p<.01$.

univariate ANOVA following multivariate analyses. After adjustment by the covariates (i.e., reading level, IQ group, and previous experience of technology use), the Rocket Reader intervention significantly affected the self-regulation score, $F(1,163)=12.47, p<.01$, partial $\eta^{2}=.07$, although we did not find a statistically significant within-subjects time effect on self-regulation scores (see Table 4). More notably, the interaction between time and Rocket Reader on the self-regulation score was statistically significant, $F(1$, $163)=8.18, p<.01$, partial $\eta^{2}=.05$ (see Table 4). These results indicate that the improvement in self-regulation was primarily due to the Rocket Reader intervention. The marginal mean self-regulation score for control group was maintained over time, but that for the experimental group markedly increased from Time $1(M=7.51, S E=0.43)$ to Time $2(M=10.21, S E=0.42)$.

\section{Self-Efficacy and Outcome Expectancy for Educational Planning}

The test for homogeneity of dispersion matrices was not significant, Box $F(10,131053)=1.19, p=.29$, so that results of evaluation of homogeneity of slopes assumption was satisfactory. A repeated measures MANCOVA revealed that the multivariate within-subjects time effect on the combined two dependent variables (self-efficacy and outcome 
expectancy for educational planning) was statistically significant, Wilk's $\Lambda=.95, F(2,162)=4.18, p<.05$, partial $\eta^{2}=.05$. Taken as a whole, self-efficacy and outcome expectancy improved between Time 1 and Time 2. Neither the multivariate between-subject Rocket Reader effect, $F(2$, $163)=0.28, p=.76$, nor the within-between interaction effect, $F(2,163)=1.64, p=.20$, was significant. In other words, there was not a significant impact of the Rocket Reader between two groups, although self-efficacy and outcome expectancy for educational planning improved for all participating students in both groups.

To investigate the impact of time on each individual independent variable, we conducted a univariate ANOVA following multivariate analyses. After adjustment by the covariates (i.e., reading level, IQ group, and previous experience of technology use), we found a significant withinsubjects time effect on outcome expectancy scores, $F(1$, $163)=0.417, p<.025$, partial $\eta^{2}=.026$, although the interaction between time and Rocket Reader on each score was not significant. That is, students' outcome expectancy score statistically improved between Time $1(M=19.04, S E=$ $0.48)$ and Time $2(M=22.11, S E=0.41)$.

\section{Understanding the Transition Planning Meeting}

Results regarding the evaluation of the homogeneity of slopes assumption were satisfactory, Box $F(3,5349775)=$ $1.86, p=.134$. A repeated measures one-way analysis of covariance revealed that the within-subjects time effect on the knowledge of transition planning was statistically significant, Wilk's $\Lambda=.97, F(1,163)=4.71, p<.05$, partial $\eta^{2}=.03$. That is, there was a systematic difference in the WFA Knowledge Test scores measured at Time $1(M=61.66$, $S E=1.12)$ and Time $2(M=74.08, S E=0.97)$. In addition, the interaction between time and Rocket Reader on the WFA Knowledge Test score was statistically significant, $F(1,163)=$ 5.94, $p<.05$, partial $\eta^{2}=.04$, although a within-subjects Rocket Reader effect was not statistically significant.

The marginal mean WFA Knowledge Test score for both groups markedly increased from Time 1 (for the control group, $M=64.26, S E=1.66$; for the experimental group, $M=59.06, S D=1.62$ ) to Time 2 (for the control group, $M=$ $74.30, S D=1.44$; for the experimental group, $M=73.86$, $S D=1.40)$. The marginal mean differences between pre- and posttest for the experimental group (19.80) was larger than those for control group (10.04). An independent samples $t$ test was conducted to evaluate if the difference between the two values was meaningful (19.80 and 10.04), and the result was statistically significant, $t(166)=2.26, p=.025$. Therefore, students who received the intervention that used a cognitively accessible computer-based reading program to enhance self-direct planning improved more on their transition planning knowledge than their counterparts did.

\section{Social Validity}

We assessed the social validity of the intervention by using teacher and student feedback forms. Out of 25 teachers, 24 reported that the WFA process provided important and relevant information about student involvement and IEP preparation. One teacher in the control group answered that transition planning information was not as relevant, because the students were only in seventh grade and not yet ready to be included; however, the teacher did report that the information was good about IEP preparation. Teachers reported that several chapters were especially relevant for their students, including chapters 1 (64\% of teachers picked this chapter), 2 (72\%), 3 (68\%), 4 (60\%), and 7 (44\%). Furthermore, 10 teachers in the experimental group and 6 teachers in the control group (16 teachers, $64 \%$ ) said that the process influenced their IEP preparation method. Twelve teachers in the experimental group and 8 teachers in the control group (20 teachers, $80 \%$ ) mentioned that they would use the WFA next year with their students. However, 5 teachers $(20 \%)$ answered that they would not, because they planned to teacher younger students. In addition, all teachers said that they would recommend this process to other teachers, especially those working with 9th and 10th graders. We did not see any huge differences of teachers' feedback between groups; however, teachers in the experimental groups may have had a tendency to be more positive than teachers in the control group.

In sum, 82 students in the experimental group (out of 86) and 67 students in the control group (out of 82) reported that the WFA notebook was easy to understand; furthermore, 36 students in the experimental group and 56 students in the control group said that it was sometimes challenging but not too hard. More than $90 \%$ of the students (81 students in the experimental group, 73 in the control group) reported that this process was influential in their IEP meeting preparation. No students reported that this process negatively affected their IEP meeting preparation. Moreover, there were several lessons that more than $50 \%$ of students reported liking, including chapters 1 (64\%), 3 (52\%), $8(53 \%), 9(58 \%)$, and $10(50 \%)$. No chapters were reported by more than $50 \%$ of students as being disinteresting, but 69 students (41\%) mentioned that chapter 2, "Disability," was not an interesting topic to them.

\section{Discussion \\ Summary of Findings}

At the outset, we should note that with regard to evaluating the effect of technology-based reading supports on student performance, this study set the bar high. That is, all students, whether in the control group or the treatment group, received 
instruction with the WFA process. Previous research has established that intervention with the $W F A$ process results in enhanced self-determination, increased knowledge about transition planning, and improved self-efficacy and outcome expectations for educational planning (Wehmeyer \& Lawrence, 1995, in press). To evaluate the impact of the Rocket Reader supports on instruction to promote student involvement and self-determination, however, we needed to ensure that all students had the opportunity to acquire such knowledge in the first place. As evidenced by mean scores and within-subjects analyses, all students benefited from the intervention. Moreover, a comparison between students receiving the $W F A$ lessons delivered by Rocket Reader and students not involved in any training pertaining to student involvement provided information about the contribution of the use of technology and the significant improvement in self-determination, specifically self-regulation.

Limitations of the study. Before discussing the findings, we should note that the study has several limitations to consider. First, some teachers and students did not complete the lesson sequence in the time given, and owing to study timeline constraints, the intervention period was relatively short. That there were significant findings despite this limitation speaks to the potential value of both instruction to promote student involvement and the use of technology to provide reading supports. Furthermore, because of the study's time constraints, only a portion of the WFA lessons were implemented. One presumes that students would have performed better had they received the full intervention; so again, that students benefited from only a small segment of the WFA lessons suggests the potential effect of implementing such practices. Third, outcome measures were based on student self-report only. We could not conduct direct observation of students' IEP or individualized transition planning meetings, because most of the students' planning meetings had already been held or were scheduled to be held after the study. However, using multiple measures, we tried to collect relevant information related to students' self-determination and participation in transition planning. Last, with regard to limitations, although we randomly assigned students to an experimental or control group, random assignment occurred at the campus level, and each student (as a subject) was nested within the unit of teacher, school, and school district. The study would have been stronger had the randomization occurred at the teacher or student level, but as indicated in the Method section, that was not possible. Using current data analyses procedures, we clearly answered the research questions above, but we could not examine those nesting variables through procedures such as hierarchical linear modeling or structural equation modeling, because of the limited number of schools in the study.

With the above caveats, the degree to which the experimental group (i.e., the students receiving instruction using the Rocket Reader) disproportionately benefited suggests the potentially strong benefit of using such technology to deliver content in student involvement instruction. With regard to the students' level of self-determination, the intervention delivered by Rocket Reader yielded a significant overall impact on two major self-determination scales. It especially did so on the Self-Regulation subscale of the Arc's Self-Determination Scale, which measured the degree to which students possessed skills related to interpersonal cognitive problem solving, as well as goal setting and task performance. For example, with a story-based format that posed a problem at the beginning and reported an outcome at the end, students were instructed to tell what happened in the middle that connects the beginning and the ending, thus demonstrating means-end problem-solving capacity. The second domain in the Self-Regulation subscale is goal setting and task performance, which are measured by asking students to identify a goal in each of three major transition areas (living, working, and transportation) and to list the steps they would need to take to meet each goal. As such, the skills measured in the Self-Regulation subscale were closely connected to what students were taught in classroom using the selected lessons from WFA, with or without Rocket Reader (e.g., goal-setting, communication); thus, progress in that domain would be expected.

That the process was effective was indicated by the significant impact of the intervention on students' understanding transition planning, as measured by WFA Knowledge Test. As noted, the WFA Knowledge Test measures understanding of, or knowledge about, transition planning meetings, such as the purpose of an educational planning meeting, the outcomes addressed in transition plans, the decision-making processes, and communication. That is, students participating in this study should have expanded knowledge of transition planning, and, in fact, they did gain such knowledge.

With regard to the students' self-efficacy and outcome expectancy for educational planning, the impact of the Rocket Reader intervention was not significant, but there was a meaningful effect of time within participants, and as such, all students significantly improved on their selfefficacy and outcome expectancy after participating in the $W F A$ process. As mentioned previously, the $W F A$ process was originally developed to promote students' preparation for the transition planning process. Given the shortened time frame for the study, we chose 10 lessons as having priority for middle or junior high school students with disabilities, focusing on self-awareness (e.g., preferences, interests, and individual unique needs), basic interpersonal communication skills, and identifying goals in the plan to meet the needs of middle school students who did not have any experience related to transition issues. Although we could not include several lessons that directly dealt with transition 
planning meetings (e.g., how to get what students need using community resources, how to manage meetings as an active team member, how to involve students' ideas at the meeting), the selected lessons of this curriculum influenced students' self-efficacy and outcome expectancy for educational planning meeting.

In general, students benefited from the WFA instruction by showing enhanced self-determination, transition planning knowledge, and self-efficacy and outcome expectations for educational planning, and students who received instruction with the process utilizing the technology-based reading support benefited even more than did their peers who did not receive that support, particularly in self-determination, self-regulation, and transition planning knowledge. As seen in the results, studentdirected transition planning instruction using the Rocket Reader did affect students' self-determination, especially student self-regulation, and it affected their transition planning knowledge. From this finding, we conclude that students who used the technology benefited more from instruction to self-direct planning than did students who did not use the technology. Moreover, that students with disabilities in this study differentially benefited from the use of technology to deliver the content in the WFA price is consistent with emerging research pertaining to universal design for learning and the use of technology to promote outcomes for students with cognitive disabilities (Wehmeyer, Smith, \& Davies, 2006). It also supports the more general finings that computer-assisted learning provides clear advantages to students with disabilities (Alcalde, Navarro, Marchena, \& Ruiz, 1998; BernardOpitz, Sriram, \& Nakhoda-Sapuan, 2001; Blischak \& Schlosser, 2003; Davies et al., 2003; Elder-Hinshaw \& Manset-Williamson, 2006; Raskind \& Higggins, 1995; Wehmeyer et al., 2006).

\section{Implications for Transition for Middle School Students}

The Individuals with Disabilities Education Act Amendments of 2004 required that students aged 16 and older be invited to attend their IEP meeting if transition services are to be discussed. That means that students need to not only learn appropriate behaviors utilized at IEP meetings but also understand issues that might be discussed therein, including transition services, before they enter the meeting itself. Several studies have emphasized the importance of starting transition planning earlier to prepare students for their transition years (Coleman, 2001; Garay, 2003). One implication for this study is that students with disabilities in middle school can benefit from instruction in student involvement and that beginning such intervention during the middle school years could lead to more positive outcomes in later years. Most studies examining student involvement were, logically, conducted with high school students or young adults (Cross et al., 1999; Fullerton, 1995; Wehmeyer, Garner, Yeager, \& Lawrence, 2006; Wehmeyer, Palmer, Soukup, Garner, \& Lawrence, 2007).

It's good to go ahead. Anecdotal information from participating teachers in this study provided further information about teaching transition planning to middle school students, about what they should be doing at IEP meetings, and about using the WFA process. Most teachers in this study agreed that the transition planning process needs to begin in middle school. One teacher said that she liked it when she did some limited transition planning with her students at the middle school age and that discussing transition outcomes was important because students would soon need to seriously consider those goals. Moreover, several teachers emphasized that middle school students should start to become aware of their unique needs to set appropriate transition goals, but one teacher indicated that teachers need more training on how to make this stage more meaningful for members of the IEP team.

What middle school students should be doing at IEP meeting. Several teachers indicated that students need to begin thinking about transition outcomes in middle school (e.g., where to live after high school, recreation options, attending any postsecondary education) so that by the time they get to high school, they can be more actively involved with their transition process. In other words, students can at least begin thinking about and identifying what they want to achieve; as such, starting discussions about transition planning gives directions for middle school students that will be of benefit when they transition to high school. However, two teachers were anxious about discussing transition with their students because they thought that (a) their students did not understand their potential future and (b) students needed to talk less about transition goals (which did not apply until age 16) and more about academic goals.

Using the WFA with middle school students. Most teachers participating in this study indicated that this curriculum influenced their students' IEP preparation. One teacher reported that she liked this curriculum because her students became more aware of what their IEPs contained and how to verbalize their preferences and interests so that they were empowered to effectively participate in their IEP meetings in terms of working with the WFA. Other teachers discussed the effective way that it walked though each lesson, which allowed them to either follow the script or modify it to best fit their students. One teacher said that his students enjoyed making and sharing lists provided in the student's notebook, which got them engaged through active participation. 


\section{Implications for Research}

With the limitations discussed previously, the results of this investigation provide suggestions for future research regarding the use of a student-directed transition planning process with a computer-based reading support program. First, the current study would have been stronger if the intervention was implemented over a longer time to ensure that students received the whole content and mastered the information. A replication doing so is thus warranted. Second, this study warrants research exploring the effect of teaching middle school students to engage in instruction to promote involvement in transition planning. Such research needs to identify what to teach that will be the most relevant for middle school students to enable them to prepare for transition planning during high school. Research also needs to examine how to enhance the understanding and preparation of teachers working with middle school students, to help them teach and facilitate students' involvement in their transition planning.

\section{Declaration of Conflicting Interests}

The author(s) declare no potential conflicts of interest with respect to the authorship and publication of this article, although it is noted that the fifth and sixth authors, who are employees of AbleLink Technologies, have used these and other research findings to develop a commercially available software product (Rocket Reader) for increasing access to literacy for people with intellectual disability.

\section{Funding}

The author(s) disclosed receipt of the following financial support for the research, authorship, and/or publication of this article: Funding for this research was provided by Grant PR Award No. H133A031727 from the U.S. Department of Education, National Institute on Disability and Rehabilitation Research, awarded to the University of Kansas, and Grant PR Award No. R324B070159 from the U.S. Department of Education, Institute of Education Sciences, National Center for Special Education Research, also awarded to the University of Kansas. The contents of this report do not necessarily represent the policy of the U.S. Department of Education, and endorsement by the federal government should not be assumed.

\section{References}

Acock, A. C. (2005). Working with missing values. Journal of Marriage and Family, 67, 1012-1028.

Agran, M., Blanchard, C., \& Wehmeyer, M. L. (2000). Promoting transition goals and self-determination through student selfdirected learning: The self-determined model of instruction. Education and Training in Mental Retardation and Developing Disabilities, 35, 351-364.

Agran, M., Snow, K., \& Swaner, J. (1999). Teacher perceptions of self-determination: Benefits, characteristics, and strategies. Education and Training in Mental Retardation and Developmental Disabilities, 34, 293-301.
Alcalde, C., Navarro, J. I., Marchena, E., \& Ruiz, G. (1998). Acquisition of basic concepts by children with intellectual disabilities using a computer assisted learning approach. Psychological Reports, 82, 1051-1056.

Bandura, A. (1977). Social learning theory. Englewood Cliffs, NJ: Prentice Hall.

Bernard-Opitz, V., Sriram, N., \& Nakhoda-Sapuan, S. (2001). Enhancing social problem solving in children with autism and normal children through computer-assisted instruction. Journal of Autism and Developmental Disorders, 31, 377-384.

Blischak, D. M., \& Schlosser, R. W. (2003). Use of technology to support independent spelling by students with autism. Topics in Language Disorders, 23, 292-302.

Cohen, J. (1988). Statistical power analysis for the behavioral sciences. Hillsdale, NJ: Erlbaum.

Coleman, M. R. (2001). Middle schools: New trends and issues. Gifted Child Today Magazine, 24, 20-21.

Cross, T., Cooke, N. L., Wood, W. W., \& Test, D. W. (1999). Comparison of the effects of MAPS and ChoiceMaker on student self-determination skills. Education and Training in Mental Retardation and Developmental Disabilities, 34, 499-510.

Davies, D. K., Stock, S. E., \& Wehmeyer, M. L. (2003). A Palmtop computer-based intelligent aid for individuals with intellectual disabilities to increase independent decision making. Research and Practice for Persons With Severe Disabilities, 28, 182-193.

Elder-Hinshaw, R., \& Manset-Williamson, G. (2006). Engaging older students with reading disabilities. Teaching Exceptional Children, 39, 6-11.

Friendly, M. (1983). Power computations for ANOVA designs. Retrieved from http://www.math.yorku.ca/SCS/sasmac/fpower .html

Fullerton, A. (1995). Promoting self-determination for adolescents and young adults with autism. Journal of Vocational Rehabilitation, 5, 337-346.

Garay, S. V. (2003). Listening to the voices of deaf students: Essential transition issues. Teaching Exceptional Children, $35,44-48$.

Green, S. B., \& Salkind, N. J. (2008). Using SPSS for Windows and Macintosh: Analyzing and understanding data. (Upper Saddle River, NJ: Prentice Hall.

Individuals With Disabilities Education Improvement Act of 2004, Pub. L. 108-446, § 601.

Izzo, M., \& Lamb, P. (2002). Self-determination and career development: Skills for successful transition to postsecondary education and employment. Columbus: Ohio State University; Manoa: Center on Disability Studies at the University of Hawaii at Manoa; Minneapolis, MN: National Center on Secondary Education and Transition.

Kleinbaum, D. G., Kupper, L. L., Muller, K. E., \& Nizam, A., (1998). Applied regression analysis and other multivariable methods. (3rd ed.) Pacific Grove: CA, Duxbury Press.

Lipsey, M. W., \& Wilson, D. B. (2001). Practical meta-analysis. Thousand Oaks, CA: Sage.

Martin, J. E., Dycke, J. V., Christense, W. R., Greene, B. A., Gardner, J. E., \& Lovett, D. L. (2006). Increasing student 
participation in IEP meetings: Establishing the self-directed IEP as an evidenced-based practice. Exceptional Children, 72, 299-316.

Mason, C., Field, S., \& Swailowsky, S. (2004). Implementation of self-determination activities and student participation in IEPs. Exceptional Children, 70, 441-451.

Mithaug, D. E., Campeau, P. L., \& Wolman, J. M. (2003). Assessing self-determination prospects among students with and without disabilities. In D. E. Mithaug, D. K. Mithaug, M. Agran, J. E. Martin, \& M. L. Wehmeyer (Eds.), Self determined learning theory: Construction, verification, and evaluation (pp. 61-76). Mahwah, NJ: Erlbaum.

National Center on Secondary Education and Transition. (2004). Current challenges facing the future of secondary education and transition services for youth with disabilities in the United States. Retrieved July 2005 from http://www.ncset.org/ publications/discussionpaper/NCSET_Discussion_Paper.pdf.

Palmer, S. B., Wehmeyer, M. L., Gipson, K., \& Agran, M. (2004). Promoting access to the general curriculum by teaching selfdetermination skills. Exceptional Children, 70, 427-439.

Power, L. E., Turner, A., Westwood, D., Matuszewski, J., Wilson, R., \& Phillips, A. (2001). TAKE CHARGE for the future: A controlled field-test of a model to promote student involvement in transition planning. Career Development for Exceptional Individuals, 24, 89-104.

Raskind, M., \& Higgins, E. (1995). Effects of speech synthesis on the proofreading efficiency of postsecondary students with learning disabilities. Learning Disability Quarterly, 18, 141-156.

Rose, D., \& Meyer, A. (2002). Teaching every student in the digital age: Universal design for learning. Alexandria, VA: ASCD.

Sands, D., Spencer, K., Gliner, J., \& Swaim, R. (1999). Structural equation modeling of student involvement in transitionrelated actions: The path of least resistance. Focus on Autism and Other Developmental Disabilities, 14, 17-27.

Shadish, W. R., Cook, T. D., \& Campbell, D. T. (2002). Experimental and quasi-experimental designs for generalized causal inference. Boston: Houghton-Mifflin.

Sherer, M., Maddox, J. E., Mercandante, B., Prentice-Dunn, S., Jacob, B., \& Rogers, R. W. (1982). The Self-Efficacy Scale: Construction and validation. Psychological Reports, 51, 663-671.

Tabachnick, B. G., \& Fidell, L. S. (2001). Using multivariate statistics (4th ed.). Boston: Allyn \& Bacon.

Test, D. W., Mason, C., Hughes, C., Konrad, M., Neale, M., \& Wood, W. M. (2004). Student involvement in individualized education program meetings. Exceptional Children, 70, 391-412.

Thoma, C., Rogan, P., \& Baker, S. (2001). Student involvement $\mathrm{n}$ transition planning: Unheard voices. Education and Training in Mental Retardation and Developmental Disabilities, 36 , $16-29$.

Wehmeyer, M. L. (1996). A self-report measure of self-determination for adolescents with cognitive disabilities. Education and Training in Mental Retardation and Developmental Disabilities, 31, 282-293.
Wehmeyer, M. L. (2005). Self-determination and individuals with severe disabilities: Reexamining meanings and misinterpretations. Research and Practice for Persons With Severe Disabilities, 30, 113-120.

Wehmeyer, M. L., Agran, M., \& Hughes, C. (2000). A national survey of teachers' promotion of self-determination and student-directed learning. The Journal of Special Education, 34, 58-68.

Wehmeyer, M. L., Garner, N. W., Yeager, D., \& Lawrence, M. (2006). Infusing self-determination into 18-21 services for students with intellectual or developmental disabilities: A multi-stage, multiple component model. Education and Training in Developmental Disabilities, 41, 3-13.

Wehmeyer, M. L., \& Kelchner, K. (1995). The Arc's SelfDetermination Scale. Silver Springs, MD: The Arc of the United States.

Wehmeyer, M. L., Kelchner, K., \& Richards, S.. (1996). Essential characteristics of self-determined behaviors of adults with mental retardation and developmental disabilities. American Journal on Mental Retardation, 100, 632-642.

Wehmeyer, M. L., \& Lawrence, M. (1995). Whose Future Is It Anyway? Promoting student involvement in transition planning. Career Development for Exceptional Individuals, 18, 69-83.

Wehmeyer, M. L., \& Lawrence, M. (in press). A national replication of a student-directed transition planning process: Impact on student knowledge of and perceptions about transition planning. Education and Treatment of Children.

Wehmeyer, M. L., Lawrence, M., Kelchner, K., Palmer, S. B., Garner, N. W., \& Soukup, J. (2004). Whose Future Is It Anyway? A student-directed transition planning process (2nd ed.). Lawrence, KS: Beach Center on Disabilities.

Wehmeyer, M. L., \& Palmer, S. B. (2003). Adult outcomes from students with cognitive disabilities three years after high school: The impact of self-determination. Education and Training in Developmental Disabilities, 38, 131-144.

Wehmeyer, M. L., Palmer, S., Smith, S., Parent, W., Davies, D., \& Stock, S. (2006). Technology use by people with intellectual and developmental disabilities to support employment activities: A single-subject design meta analysis. Journal of Vocational Rehabilitation, 24, 81-86.

Wehmeyer, M. L., Palmer, S., Soukup, J. H., Garner, N., \& Lawrence, M. (2007). Self-determination and student transition-planning knowledge and skills: Predicting involvement. Exceptionality, 15, 31-44.

Wehmeyer, M. L., \& Schwartz, M. (1997). Self-determination and positive adult outcomes: A follow-up study of youth with mental retardation or learning disabilities. Exceptional Children, 63, 245-255.

Wehmeyer, M. L., \& Schwartz, M. (1998). The relationship between self-determination and quality of life for adults with mental retardation. Education and Training in Mental Retardation and Developmental Disabilities, 33, 3-12. 
Wehmeyer, M. L., Smith, S., Palmer, S., \& Davies, D. (2004). Technology use by students with intellectual disabilities: An overview. Journal of Special Education Technology, 19, 7-22.

Wolman, J., Campeau, P., Dubois, P., Mithaug, D., \& Stolarski, V. (1994). AIR Self-Determination Scale and user guide. Palo Alto, CA: American Institute for Research.

Zhang, D. (2001). The effect of Next S.T.E.P. instruction on the self-determination skills of high school students with learning disabilities. Career Development for Exceptional Individuals, 24, 121-132.

Zhang, D., \& Stecker, P. M. (2001). Student involvement in transition planning: Are we there yet? Education and Training in Mental Retardation and Developmental Disabilities, 36, 293-303.

\section{About the Authors}

Youngsun Lee, $\mathrm{PhD}$, is a full-time lecturer of special education in Department of Education, Inha University, South Korea. Her research interests include self-determination, transition planning, and technology use for secondary students with disabilities.

Michael L. Wehmeyer, $\mathrm{PhD}$, is a professor of special education, director of the Kansas University Center on Developmental Disabilities, and senior scientist and associate director at the Beach Center on Disability. His research focuses on self-determination, access to the general education curriculum for students with severe disabilities, and technology use by people with cognitive disabilities.

Susan B. Palmer, PhD, is a research associate professor at the University of Kansas and is affiliated with the Beach Center on Disability, the Kansas University Center on Developmental Disabilities, and the Department of Special Education. She is interested in self-determination and access to the general curriculum for students of all ages.

Kendra Williams-Diehm, $\mathrm{PhD}$, is an assistant professor at the University of Oklahoma in the Department of Education Psychology, Jeannine Rainbolt College of Education. She currently conducts research on self-determination and transition/ postsecondary outcomes for students with disabilities.

Daniel K. Davies, MA, is the president and founder of AbleLink Technologies in Colorado Springs, Colorado. His interest is in the research and development of technology to support independent functioning and quality of life for people with cognitive disabilities.

Steven E. Stock, MA, is the vice president of AbleLink Technologies in Colorado Springs, Colorado. His research has been primarily in the areas of developing assistive technologies to support independence for individuals with developmental disabilities, traumatic brain injuries, and aging and dementia issues. 